\title{
The Application Research of Geography Teaching with ERDAS Software in the Middle Schoo**
}

\author{
Hailing Jiang \\ College of Tourism and Geographical Science \\ Jilin Normal University \\ Siping, China 136000 \\ Xinyu Wang \\ College of Tourism and Geographical Science \\ Jilin Normal University \\ Siping, China 136000

\section{Shuang Li} \\ College of Tourism and Geographical Science \\ Jilin Normal University \\ Siping, China 136000
}

\author{
Shixin Zheng \\ College of Tourism and Geographical Science \\ Jilin Normal University \\ Siping, China 136000 \\ Xiuhua Zhang \\ College of Tourism and Geographical Science \\ Jilin Normal University \\ Siping, China 136000 \\ Jiaojiao $\mathrm{Su}$ \\ College of Tourism and Geographical Science \\ Jilin Normal University \\ Siping, China 136000
}

\begin{abstract}
With the development of satellite remote sensing technology, remote sensing image has become an important data source gradually for modern Geo-science analysis and research. Among the massive Multi-source Remote Sensing data, the processing of Remote Sensing image is considered as a crucial mean to achieve image data mining and knowledge discovery. Therefore, ERDAS software will play a significant role in the geographical teaching and reforms, with its advantage as an important tool and platform for remote sensing data analysis. Based on the introduction of the characteristics of ERDAS software, the specific application of ERDAS in middle school geography class is also proposed, concluding mobilizing students' subjective initiative in learning, improving teaching effect, establishing an open geography class, and improving students' foreign language level and operational ability. Then, the key methods of images preprocessing are introduced in the application of ERDAS software. Finally, practical problems of ERDAS software applications are analyzed. In conclusion, the present study provides an important reference value for improving the quality of geography teaching in junior high school.
\end{abstract}

Keyswords-ERDAS software; teaching reform; geography teaching in middle school

\section{INTRODUCTION}

With the continuous advancement of the new curriculum reform, traditional teaching modes no longer meet the needs of modern teaching [1][2][3]. Based on the rapid

*Funded projects: The education department project of Jilin province (Jijiaokewenhezi No.172 [2016]), The national natural science foundation of China (41701424), the open research fund project of national key laboratory of remote sensing science (OFSLRSS201716), the education department project of Jilin province (No.172 [2016]). development of modern teaching technology, especially $3 \mathrm{~S}$ technologies which were remote sensing (RS), geography information systems (GIS) and global positioning systems (GPS), teaching methods of geography in middle school has been improved significantly. Especially teaching modes of geography in middle school was greatly enriched by the application of remote sensing technology [4] [5]. Thus, there were many papers introducing the application of Remote Sensing technology for geography teaching in middle school. However, with the large storage capacity (A Landsat8 OLI image of over $1 \mathrm{G}$ ) and various storage formats, downloaded from the Internet, the original remote sensing images that downloaded from the Internet were difficult to be opened directly by the traditional display software. Therefore, in this paper, ERDAS IMAGINE was introduced as professional software for the remote sensing images processing. Meanwhile, its application was expounded for geography teaching in middle school. Developed by company ERDAS in U.S, ERDAS IMAGINE have powerful functions of images processing, a high degree of integration on $3 \mathrm{~S}$ technology, and optimal algorithms of images processing. Besides, based on its unique functions of data processing, it can be applied to geographical teaching in middle school. Students' subjective initiative in geographical learning would be aroused. In addition, teaching effects of class also would be improved. Accordingly, an active and open geography class would be constructed.

\section{ERDAS SOFTWARE OVERVIEW}

\section{A. The Characters of ERDAS Software}

Developed by company ERDAS in the United States, ERDAS IMAGINE was defined as systematic software for 
processing remote sensing images. With the advanced functions of image processing, friendly and flexible user interfaces and operation modes, modules for wide application areas, models development tools for different levels of users, and high-level integrated function of remote sensing image processing, it not only provided a rich and powerful tool of images processing for users in remote sensing and related application fields, but also represented the future development trend of processing system for remote sensing images. Major modules included in EADAS were as follows: Core module, image processing module, terrain analysis module, digital module, scanner module, grid GIS module, and hard copy module, tape machine module, etc. The images processing module included the enhancement module, pre-classification module, classification module, post-processing module, radiation correction module and geometric correction module.

\section{THE APPLICATIONS OF ERDAS SOFTWARE}

There were many processing techniques of ERDAS software: the input/output of images, images enhancement, geometric correction, data resolutions and transformations, information extraction, spatial analysis and modeling, expert classifications, updates of Arc Info vector data, digital photogrammetry and 3D information extraction, hardcopy maps output (clear and abundant paper maps), radar data processing, and 3D display analysis. Adapting to all UNIX systems, PC Microsoft Windows 2000Professional, as well as Windows XP professional operation systems, applications field of ERADS software have been involved in scientific research, environmental monitoring, meteorology, exploration of petroleum and mineral, agriculture, medicine, military (digital geographic battlefield), telecommunication, cartography, forestry, natural resource management, utility management, engineering, hydraulic engineering, marine, surveying and mapping, reconnaissance, urban and regional planning.

\section{COMPARISONS BETWEEN ERDAS AND OTHER SOFTWARE OF REMOTE SENSING}

The advantages of ERDAS software as follows: First of all, with integrated functions, user interfaces and operation modes were friendly and flexible. Secondly, developed by professional companies and technical teams, the technology of images processing was advanced. Thirdly, with all-sided and detailed operation steps, instruction books were classical. There were still shortcomings. For example, only the data types that distinguished by ERDAS software can be opened. Converting ".dat" data format of Landsat TM into ".img", then, it can be added to the viewer window of ERDAS.

Nowadays ENVI software also is one of the most popular remote sensing software. As for its advantages, data formats needn't to be converted, and the data formats of advanced satellites can be processed. For example, opening ENVI software, selecting the satellite and the corresponding sensors, corresponding data can be opened directly. Moreover, bands needn't to be synthesized, and multiple bands of images can be opened simultaneously. Through "saving as" module, images can be converted and stored in required formats. For disadvantages, functions were not integrated and scattered.

Even though IDRISI wasn't the frequently-used software, it combined GIS and functions of image processing, professional, practical, and shaped function modules were provided. Meanwhile, the software was added the functional modules which combine theory, edging technology, and new results. However, its technology of images processing was weak, besides, operating books were lacking.

In the applications of ERDAS software for geography teaching in middle school, firstly the receptivity of teachers and students need to be taken into account. In addition, it was necessary to have systematic distributions of software functions and professional books. Secondly, as nonprofessional users, teachers and students only need simple data sources and convenient steps of data processing and analysis. In summary, ERDAS has been considered as the most suitable software for geography teaching in middle school.

\section{APPLICATIONS OF ERDAS SOFTWARE OF GEOGRAPHY TEACHING IN MIDDLE SCHOOL}

\section{A. Mobilizing Students' Learning Initiative by ERDAS}

In the process of classroom teaching, geographical teachers of middle school usually use multimedia courseware, such as PowerPoint (PPT), text materials supported by pictures, charts, video and audio. Under this circumstance, students learn passively in a configured mode. In addition, with multitudinous ways to acquire knowledge in today's information age, middle school students can quickly acquire knowledge and broaden horizons through the Internet, which makes that traditional multimedia technology no longer stimulate students' enthusiasm for learning. Conversely, based on the interactive teaching using ERDAS software, students were able to participate in the practical process of operating software and acquire knowledge.

For example, in the teaching of "industrialization and urbanization", the fourth chapter of geography (People Education Press edition, volume 3), students practically operate ERDAS. Through the function of overlapping display in ERDAS software, images of the city where the school was located (such as 10a interval scale) were dynamically display. Students can actively understand the expansion of urban built-up areas and feel the dynamic process of urbanization. Then relying on the function of the virtual geographic information system (Virtual GIS) in ERDAS, the back-end database was used to build 3D modeling and simulate urbanization and industrialization. Through visual presentations to the information of geography teaching, students transform the passive receiver into the active participant, which can stimulate students' interest in geography learning and clarify their motivation and building confidence of geography learning. 


\section{B. Enhancing Teaching Effectiveness by ERDAS}

In the face of many difficult knowledge points of geography teaching in middle school, students were difficult to understand those abstract problems by teachers' explanations. However, based on the auxiliary teaching of ERDAS software, students can intuitively understand the characteristics and laws of spatial distribution on geographical objects, the formations and evolution process of geographical phenomena, furthermore, students can cultivate improve abilities of spatial and temporal thinking. There were some examples as follows. With the help of ERDAS, geographical spatial data that was downloaded from the cloud platform of Chinese Academy of Sciences was handled, then students can clearly identified the direction of mountains and rivers, three-level ladder terrain and topographical features, and spatial distribution of lakes, etc. Besides, based on the change detection function of the software [6-7], the differences were calculated for the multitemporal images in the same area, which can import result files in which the change areas were showed by the defined threshold values. On the basis of results of images processing, the developments and changes of geographical things can be observed and identified, so that the geographical process can be understood and mastered preferably by students.

For example, in the study of "Natural Disasters", GEOGRAPHY (PEP edition, volume 5), when talking about typhoon disasters, teachers can instruct students to open the data of china "Fengyun" static meteorological satellite at hourly intervals by ERDAS software. And then, the moving track, moving rate and changes of atmospheric circulation could be intuitively showed, simultaneously, the formation, development and evolution process of typhoon could be tracked. Finally, students were guided to be familiar with the meteorological knowledge, in addition, students think about how to prevent and mitigate disasters, and evaluate and analyze disasters impacts. In the teaching of "natural disasters", the first chapter of China's natural environment, Geography (PEP edition, grade 8), first of all, teachers can guide students to download images of disaster areas (earthquake-stricken areas in Wenchuan county) from the Chinese geospatial data cloud. Secondly, imported into ERDAS, images were operated by simple corrections, bands synthesis, etc.. Thirdly, extracting distribution information of buildings and secondary disasters by supervised classification, unsupervised classification and object-oriented ways in ERDAS, students can observe earthquake impacts on areas by right of comparing classified images before and after disasters occurrences (assessment of post-earthquake information of landslides and economic damage, etc.). In hands-on operations, students learn about knowledge, have a basic understanding of the political, economic, and cultural influences that were brought by earthquakes. In addition, students' curiosities about geography were also cultivated. Due to analyzing natural disasters, the social responsibility of students could be trained because of the analysis of national geological disasters.

\section{Building an Open and Autonomous Geography Class by ERDAS}

Nowadays, because of frequent knowledge update in information society, teachers can't teach all the knowledge points in class. Therefore, it was vital to create opening-up class of geography. That is, giving part of learning tasks to students after class, students need to collect required images independently through the URL of downloading images resources, and use ERDAS software to targeted geo-analysis. And then students can cultivate the learning ability of independent inquiry. In the process of open learning, when to analyzing data using ERDAS, students can also have indepth discussions with other students, and share problems and solutions that they encountered. Consequently, students not only cultivate abilities of communication and cooperation with each other, but also improve abilities to identify and solve problems.

For example, when studying changes of land use types in a certain area, it was hard to illuminate the trends and causes of land use types vividly by simple words and pictures. ERDAS software could be used to solve these problems. Firstly, Distributing images with different time phrases of same areas to students in class, Students classify land use types in the study areas using diverse classification methods (Supervised and Unsupervised Classification), which strengthen students' understanding of land use types. Then, the classification results of different methods and different time phases were compared and analyzed among students, which contribute to interactions between students and the grasp of basic knowledge points. When talking about the chapter of "China's natural resources distribution", Geography (People's Education Edition, eighth grade), teachers lead students to download images of specific areas for analyzing land use types. classifying by classification tools of ERDAS and analyzing classification results, the distribution and utilization of resources in a certain area were obtained (water resources, forest resources, land resources, etc.). By means of analysis methods just learned, students can study the whole region of China by observing the map on the textbook. At last, students study research methods of geography, and systematically summarize the scattered contents of multiple chapters in the textbook. Furthermore, students can improve their self-learning ability and cultivate stronger awareness of teamwork.

\section{Improving Students' English and Operational Ability}

At present, English courses have been offered at various degrees in universities, primary and secondary schools in China. However, due to limited amount of foreign language classes and the low correlation between learning contents and professional knowledge, it was difficult to achieve idea results of learning. As a result, professional English of graduates can't meet the needs of employers and graduate student in the future. Therefore, in order to improve the professional English of Chinese university undergraduates, it was imperative to add "bilingual teaching" in class.

English has been regard as the display language ERDAS software. In the process of operating the ERDAS software, students can strengthen the memory of the professional 
nouns in different function modules, and accumulate plenty of English keywords in remote sensing. On this basis, students can further study and apply Remote Sensing techniques, and express fluently applying professional English.

For example, in order to improve the contrast of satellite images and observe the ground information more intuitively and clearly that we were interested in, the function of the Histogram Matching and Histogram Equalization modules need to be applied. In the process of operation, Students can master the professional nouns that related histogram, and distinguish the nouns with similar meanings. At the same time, students' abilities of computer operations can also be exercised by plenty operations of software, which lays a good foundation for using other software in the future. For example, processing images with certain formats or achieve specific functions, ENVI (The Environment for Visualizing Images) and PCI can be used as two kinds of processing software for images. Based on the experiences accumulated in operating ERDAS software, when using other software, students will quickly master relevant skills and key techniques, and solve problems with ease.

\section{E. Cultivating Students' Ability of Systematic Thinking}

Remote sensing, an important mean of collecting earth data and changing information, has been widely used in worldwide and many institutions. However, the premises of use were that we were capable of analyzing and processing remote sensing data systematically and logically. In ERDAS software, data processing and functions realization were progressive layers. Hence at the leading of the system, students from the initial simple steps to the complex steps. After problems were solved, students review the operation steps and have a good grasp of entire data disposing. Having ideas for the same types of problems through a lot of exercises, when encountering other problems, they can have clear steps and logical thinking to deal with problems and solve problems. For example, analyzing the surface reflectivity in a certain area, students who often deal with land use types will consider analyzing the changes of land covering firstly, while students without systematic knowledge can't find a breakthrough point to solve this problem. Each operation step was exactly as same as the research process. Therefore, the good use of ERDAS software will gradually improve our ability of systematic and logical thinking.

\section{F. Promoting Students to Recognize New Technologies}

At present, remote sensing has not been offered in universities as a major. Only the related major of geographic information science (GIS) was set up. Systematic, professional learning for remote sensing was carried out from graduate level. Therefore, the public has the limited cognition about remote sensing basic theory. As a result, high school students tend to choose popular and well-known college majors while ignoring GIS. These lead to limited amounts of students in the master's degree in remote sensing. However, based on the wide application of remote sensing in various fields, such as meteorological researches, environmental protection, resource surveys, urban planning, forestry, agriculture, etc., more and more professionals of remote sensing were needed for promoting social development and economic development. Through the use of ERDAS software in geography teaching in middle school, remote sensing technology can be understood by more people. Simultaneously, students can participate in the technical process of remote sensing, which helps students to understand and develop interests on remote sensing in advance. On this basis, the field of remote sensing can be provided more talents.

\section{The StePs of Processing Remote SENSING IMAgeS USING ERDAS SOFTWARE}

Belonging to non-professional users of software, teachers and students in middle school lack of basic knowledge of remote sensing and operational ability of ERDAS software. In order to improve the accuracy of images processing and apply images in class preferably, the overall use steps of images were summarized as follows: data downloading, data processing and data analysis. In addition, on the basis of the professional knowledge of theory and technology, the common methods of images preprocessing and detailed operation steps were sorted, summarized and enumerated to satisfy the needs of teachers and students.

\section{A. Introductions of Preparations}

URLs of downloading data were Geospatial data cloud and http://golvis.usgs.gov/. Moreover, professional books were regard as references for basic knowledge and basic knowledge, for example, Mei Anxin, etc., Introduction to Remote Sensing, Higher Education Press, as well as Xin Yang, ERDAS IMAGE Remote Sensing Image Processing Method, Qinghua University Press.

Remote sensing image preprocessing means that images were processed by various processing methods, so that they can fit demands of analysis and applications. The reason for data processing as follows: In the process of collection, transfer, store, the qualities of images can't adapt the requirements of analysis and applications because of influences of various factors. For example, the reflection, absorption and scattering of atmosphere, the interference of ground objects, the changes of the ground objects, the types and errors of sensors, etc.

\section{B. Common Methods for Data Preprocessing}

The data formats refer to the recorded formats of data involving numerical values, characters, binary system, etc. Due to different methods and platforms of collecting data, geographic data was stored in different data formats. When used, data need to be converted to uniform data formats, or to data formats that used frequently, which was called "the conversion of data format". However, because the data formats that provided in ERDAS reach 156 kinds [8], beginners choose them difficultly. In summary, data formats of "Landsat" data need to be converted ".dat" file to the ".img". (1.6.1, reference book) 
Collected data was affected by many factors, such as the motions of the remote sensing platforms, terrain fluctuation, surface curvature, atmospheric refraction, etc. Consequently, images were overall distorted or non-corresponding exactly with ground; in addition, the shapes of objects on images were irregularly changed. "geometric correction" can be employed here for interpretation analysis (2.1.3, reference book). During the operation, choices of control points were the key points of geometric correction. The sources of points mainly were topographic maps, images with geometric correction, purchased vector data, and so on. When selecting control points on images, Elaborate and easily distinguished points should be selected as control points, such as road intersections, river intersections, building edges, etc. [9]

Sensors record information of ground objects using multiple bands in gathering images. In order to obtain information that we were interested in and improve the pertinence of processing and analysis, useful data in the multi-source data should be used flexibly. By combining multiple bands images to highlight information, "Images resolution" includes several forms, such as the images combination of same sensors, the images combination of different sensors, and the combination of images data and non-images data. Among them, images combination of same sensors, also known as band synthesis, can be applied to geography teaching in middle school. With simple operation, it was easy to be mastered by teachers and students (7.3.8, reference book).

In actual work, the data of research areas that was required by users may be in different images. Under this circumstance, "Images mosaic" needs to be applied to joint two or more images into a new image (2.2, reference book). On the contrary, only needing a small part for a large range of image, images need to be cropped to save storage space of disks and reduce time of data processing, which was called "image subset" (2.4, reference book).

Depending on "images interpretation", ground objects were identified from images; meanwhile, information of objects can be extracted. There were two kinds of interpretation methods: manual visual interpretation and computer interpretation. According to relatively convenient, simple and fast operations, unsupervised classification, which belongs to computer interpretation, can be utilized to geography teaching in middle school (4.1, Reference Book).

\section{CONCLUSION}

In the geography teaching, teachers carry out teaching practices more conveniently by ERDAS remote sensing software. Through visual and vivid presentation forms for images and demonstrate operations using specific data, teaching content of geography in middle school were presented in more abundant forms, which stimulates students' strong interest in learning geography. Besides, analyzing and exploring on the basis of practical operations, students can deepen their cognition and understanding of basic theory knowledge and improve practical abilities of remote sensing geo-analysis. Depending on many advantages of ERADS software, for example, friendly and flexible interface, easy operation, as well as utilization potentiality of geography teaching in middle school, students' ability of geographical space-time thinking can be effectively cultivated. Furthermore, agreeing with the new curriculum reform, the ultimate goal was expected to achieve for promoting all-round development of students. With the rapid development of remote sensing technology and further applications in geography, ERDAS software will be used as a key technology to assist geography teaching in middle school.

At present, the idea of ERDAS software was only be proposed simply. In the implementation of the application, lots of problems remain to be solved.

For the education departments, on one hand, the benefits of proper learning and use of ERDAS software have not been recognized. For example, enrich students' learning life, improve students' practical ability, intuitively understand geographical objects and geographical phenomena, and deepen and strengthen the memory of theoretical knowledge, and so on. On the other hand, there were no relevant polices and documents for applying ERADS to geography classes. Thus teachers and students have no understanding for the applications of ERDAS software.

Due to the lack of funds, schools were difficult to open computer rooms and purchase software. In addition, it was necessary to consider the scheduling time and quantities of the ERDAS course.

First of all, as non-professional characters, teachers and students were unfamiliar with ERDAS software, which brings certain difficulties in starting of use. For example, geographical teachers learn more about theory knowledge of geography at undergraduate and graduate school, instead of operations to ERDAS software. Therefore, they usually lack technical knowledge of operating software. Secondly, Due to a mass of professional terms involved ERDAS software and lacking of basic knowledge of remote sensing, even if teachers and students buy corresponding books, they were still difficult to understand operations. Thirdly, middle school students have more homework after class and have less spare time, while it takes some time to learn ERDAS software after class. Fourthly, teachers and students don't know the necessary steps, key steps and key points, which bring arbitrary and blind operations. Moreover, redundancy and inaccuracy of introduces operations on the Internet, exploring useful information takes a lot of time, which was adverse to teaching and learning.

Being limited by factors, some countermeasures of ERDAS software applications can be put forward. For example, through consulting professionals and professional professors, reasonable documents will be enacted by the education department to explain the application of ERDAS software in teaching. The pilot schools will be opened and the application situations of ERDAS software will be examined. The training courses of software system will be organized so that teachers can learn the key methods and steps of data processing and analysis. 


\section{REFERENCES}

[1] Borzuchowski J, Schulz K. Retrieval of LAI and Soil Water Content Using Hyperspectral Remote Sensing under Controlled Glass House Conditions for Spring Barley and Sugar Beet. Remote Sensing, 2010, 2(7): 1702-1721.

[2] Li Sheng-yong, Wang Xiao-qing, Li Biao. Spatio-temporal Analysis of Vegetation Cover Change Based on MODIS data in Horqin District[J]. Journal of Yangtze River Scientific Research Institute. 2016, 33(02): 118-122,127.

[3] Han Jin-xian, Duan Yong-hui. Practice Teaching Mode and Content Discussion on Physical Geography. Science and technology of Heilongjiang,2016, 6:83-84.

[4] Sun Shou-tao, Wang Li, Che Ke-jun. Analysis of Vegetation Coverage Change in Diebu Forest of the Upper Bailong River Base on Landsat Satellite Data[J]. Journal of Sichuan Agricultural University, 2016, 34(1): 39-47.

[5] He Hong,Niu Shuwen,Qi Jinghui.Vegetation in the Harten River basin in the alpine and arid regions of Northwest China : variation and response to climate change[J]. Journal of Glaciology and Geocryology. 2015, 34(4): 963-972.4

[6] Han Fei, Cheng Peng-gen, Wu Jian, Xiao Gen-ru. Research on Land Degradation Indicator based on Hyperion Data[J]. Journal of DongHua University of technology ( Journal of Physical GeoGraphy), 2008, 31(1): 45-49.

[7] Tong Q, Zhang B, Zheng L. Hyperspectral Remote Sensing: Principle, Technology and Application. No.4 De Wai Street, XiCheng District, Beijing, Higher Education Press, 2006.

[8] Yang Wei, Tang Guoan. ERDAS remote sensing digital image processing experimental tutorial. Science Press, 2009.

[9] Mei Anxin, Peng Wanglu. Introduction to Remote Sensing. Higher Education Press, 2001. 